This item was submitted to Loughborough's Institutional Repository (https://dspace.lboro.ac.uk/) by the author and is made available under the following Creative Commons Licence conditions.

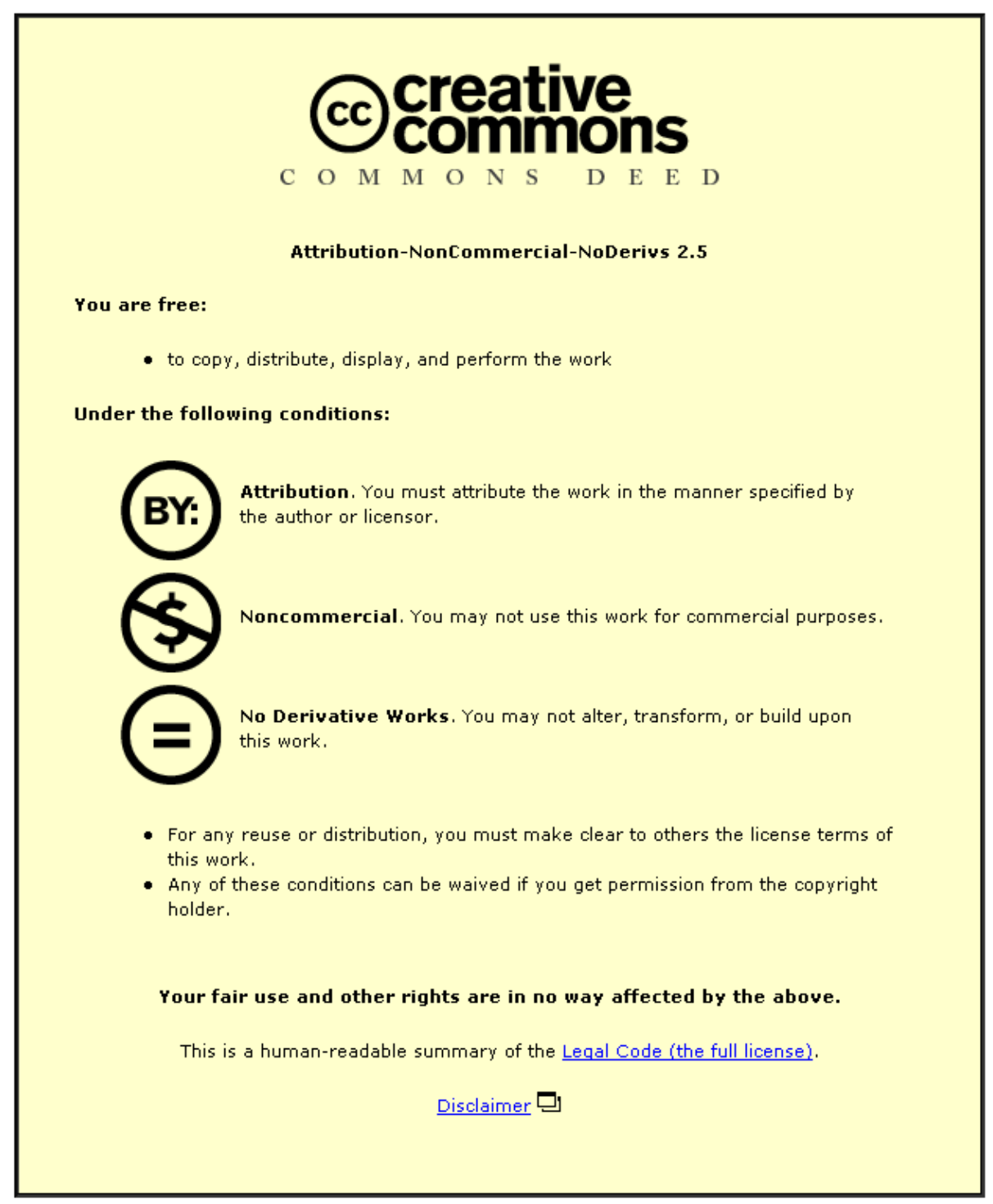

For the full text of this licence, please go to: http://creativecommons.org/licenses/by-nc-nd/2.5/ 


\title{
Evaluation of the controls affecting the quality of spatial data derived from historical aerial photographs
}

\author{
Jan Walstra ${ }^{1}$, Jim H. Chandler ${ }^{2}$, Neil Dixon ${ }^{2}$ \& Rene Wackrow ${ }^{2}$ \\ ${ }^{1}$ Department of Languages \& Cultures of the Near East \& North Africa, Ghent University, Ghent, Belgium \\ ${ }^{2}$ Department of Civil and Building Engineering, Loughborough University, Loughborough, UK
}

\section{Abstract}

This paper is concerned with the fundamental controls affecting the quality of data derived from historical aerial photographs typically used in geomorphological studies. A short review is provided of error sources introduced into the photogrammetric workflow. Datasets from two case-studies provided a variety of source data and hence a good opportunity to evaluate the influence of the quality of archival material on the accuracy of coordinated points. Based on the statistical weights assigned to the measurements, precision of the data was estimated $a$ priori, while residuals of independent checkpoints provided an a posteriori measure of data accuracy. Systematic discrepancies between the two values indicated that the routinely used stochastic model was incorrect and overoptimistic. Optimised weighting factors appeared significantly larger than previously used (and accepted) values. A test of repeat measurements explained the large uncertainties associated with the use of natural objects for ground control. This showed that the random errors not only appeared to be much larger than values accepted for appropriately controlled and targeted photogrammetric networks, but also small undetected gross errors were induced through the 'misidentification' of points. It is suggested that the effects of such 'misidentifications' should be reflected in the stochastic model through selection of more realistic weighting factors of both image and ground measurements. Using the optimised weighting factors, the accuracy of derived data can now be more truly estimated, allowing the suitability of the imagery to be judged before purchase and processing.

Keywords: digital photogrammetry, historical aerial photograph, data quality, error assessment

\section{Introduction}

Photogrammetry is an effective tool in geomorphological studies (Lane et al., 1993; Chandler, 1999). Aerial photographs not only give a qualitative description of the Earth's surface, but also provide a metric model from which quantitative measurements can be obtained. The photographic film archive is increasingly accessible to the public (e.g. USGS, 1997; NAPLIB, 1999) and a suitable sequence over time representing a site allows morphological changes to be determined if appropriate photogrammetric methods are used. The automation afforded by modern digital photogrammetric techniques have allowed for rapid and cost-effective data collection (Chandler, 1999; Baily et al., 2003).

An important aspect of any quantitative analysis is assessing the quality of data. As pointed out by some authors (Fryer et al., 1994; Cooper, 1998; Lane et al., 2000), the ease of which terrain data may be generated using highly automated techniques has focussed attention more on the analysis and interpretation of results and less on the issues of data quality. Digital 
Elevation Models (DEMs) are by far the most commonly used photogrammetric product among geomorphologists and an important aspect of their creation is stereo-matching based on automated algorithms. Many users typically consider these automated procedures as being the single most important factor affecting DEM quality, thereby overlooking the importance of the underlying photogrammetric model. Lane et al. (2000) thoroughly explored the effects of automated stereo-matching on overall surface representation, but concluded these were only little, and it is rather the design of the photogrammetric survey that is of primary importance. Hence, whether data processing is manual or automated, the fundamental controls of image geometry and image coordinate precision are of primary importance for data quality. These are known as first and second order photogrammetric network design (Fraser, 1984; Cooper, 1987; Fraser, 2007).

What is perhaps more surprising is the lack of research that has focussed on these conventional controls in a consistent way. In geomorphological studies, often material is used that is readily available, but not intended for such use. Some claims made for accuracy are based on conventional air surveys collected for mapping purposes, while others are based on very case-specific studies. Moreover, examples in literature rarely use propagation of variance to estimate precision of derived parameters as a function of the precision of the original source data (Fryer et al., 1994). This is a crucial practice, especially when dealing with archival material with little control over source data quality, and the required accuracy should be considered beforehand.

The aim of this study is to evaluate the fundamental controls on photogrammetric data quality in the context of archival (film) imagery. The outcomes should allow the formulation of $a$ priori measures of data accuracy based on the characteristics of available material. Such information would be of great value to users of historical imagery, as it allows their suitability for the intended purpose to be judged prior to purchase and processing. Two case-studies (Walstra et al., 2007) provided the necessary variety of source data for these explorations.

Although digital airborne cameras have been around for a decade now, film cameras are still widely employed (Cramer, 2005; Petrie and Walker, 2007) and, of course, remain the primary origin of archival material. This study is therefore concerned only with (scanned) material from film archives.

\section{Photogrammetric principles: functional and stochastic model}

Restitution is the procedure of establishing appropriate functional and stochastic models for describing the relationship between ground and photo coordinates. In many modern software systems, analytical photogrammetry methods established 30-100 years ago provide the basis for the restitution.

\section{The functional model}

Analytical photogrammetry entails the formulation of a rigorous mathematical relationship between measured ground and photo coordinates, and camera parameters. The main principle is the concept of collinearity, in which an object, the projection centre and its corresponding point appearing on the focal plane of the camera, all lie along a straight line. Based on this principle, and provided that the interior and exterior orientation of the camera are known, 3D coordinates can be extracted from a stereo-pair of photographs. 
For aerial film cameras, calibration certificates include the parameters of interior orientation: the location of the principal point, focal length, photo coordinates of the fiducial marks, and measures of lens distortion (Wolf and Dewitt, 2000). The exterior orientation parameters, representing the position and orientation of each photograph (typically unknown before the advent of GPS and inertial navigation systems), need to be resolved in a so-called "bundle adjustment". This is an iterative procedure in which the positions of the frames are simultaneously determined in a single least squares solution and involving linearized collinearity equations. Tie points connect adjacent photographs, while control points fix the solution into an object coordinate system. The unknowns associated with a bundle adjustment are the object coordinates of the tie points and the exterior orientation parameters of all photographs. The measured elements include the photo coordinates of tie and control points, and ground coordinates of control points, all weighted according to their presumed precision. Advantages of the procedure include: mathematical rigour, reduced ground control requirements and the minimisation and distribution of errors among all image frames.

For accurate photogrammetric work, corrections need to be made for various effects, which otherwise may result in systematic errors. These include: lens and film distortions, atmospheric refraction, earth curvature and deformation of the photos during the developing process and storage (Jacobsen, 1998; Wolf and Dewitt, 2000). The scanning process, which is an unavoidable practice when converting historical (film) imagery into digital form, may introduce further distortions.

The bundle adjustment offers the flexibility of incorporating additional parameters for estimating unknown camera parameters (if there is no calibration certificate available) and any systematic distortions. In that case, the procedure is known as a "self-calibrating bundle adjustment" (Brown, 1956; Kenefick et al., 1972; Granshaw, 1980; Chandler and Cooper, 1989). However, the inclusion of extra unknowns requires more measurements and significant correlation between parameters may lead to unsatisfactory results.

Once the mathematical relationship between the photographs and the ground surface has been established, coordinates can be extracted from anywhere on the site, and used to create DEMs and orthophotos. Since the 1990s, significant developments in digital photogrammetry have allowed automation of large parts of the photogrammetric workflow (e.g. Schenk, 1996), but detailed description of these are beyond the scope of this paper.

\section{The stochastic model}

Measurements can be regarded as random variables. By eradicating gross errors and minimising the effects of systematic errors it can be assumed that only random errors remain. These can be described by the variances of the measurements, the so-called stochastic model. The inclusion of a stochastic model in a bundle adjustment allows measurements of differing quality to be combined in a rigorous way. All measurements are weighted according to their prescribed variances, which are subsequently propagated through the functional model, thereby providing estimates of the variances of derived data (Cooper and Cross, 1988; Butler et al., 1998).

All of these functional and stochastic aspects are of great importance when historical photographs are used. The perfect historical data set is rarely available and the lack of 
redundant imagery requires judgement to assess whether an appropriate stochastic and functional model has been achieved.

\section{Data quality: controls and evaluation}

As defined by Cooper and Cross (1988), the quality of derived data is a function of the precision, accuracy and reliability of the measurements and the functional model used. Precision can be related to random errors inherent in any measurement procedure, accuracy can be associated with systematic errors in the model, while reliability refers to the presence of gross errors.

\section{Precision}

The precision of image measurements is inherent to the source data, and a function of the resolving power or sharpness of the lens and film used. The resolving power of a photograph can be described by its spatial frequency (lines/mm) and the contrast. The resolving power of a typical photogrammetric camera is usually limited by the film rather than by the lens or image motion during exposure (Slama, 1980). Other factors are the atmospheric conditions, target contrast, and film processing. The grain size of the silver crystals in film emulsions provides a much better resolving power than can be achieved using paper prints. In general, colour films are grainier than black-and-white film, and grains tend to be larger in older material due to lower quality of the emulsions (Lo, 1976).

Although the pixel resolution is an important control for both scanned, and indeed directly acquired digital, imagery, the quality of the lens remains paramount (Thomson, 2010). In order to preserve an original film resolution of 30-60 lines $/ \mathrm{mm}$, a scanned pixel size of 6-12 $\mu \mathrm{m}$ would be needed. For many practical applications, such as DEM generation, good results can be achieved with 25-30 $\mu \mathrm{m}$ resolution (Baltsavias, 1999).

The effects of photo-scale and image resolution can be combined conveniently in terms of ground resolution, which determines the level of horizontal detail in object space that is visible on the photographs (Lillesand and Kiefer, 1994). Using trigonometry, an approximate estimate for the corresponding vertical resolution can be obtained by multiplying the horizontal ground resolution with the inverse base/height ratio (Equations 1 and 2). It follows that a strong convergence (large base/height ratio), and consequently large relief displacement, gives rise to precise vertical object coordinates (Wolf and Dewitt, 2000).

(Equation 1) $H R=\frac{S}{r}=s_{x} \cdot S$

(Equation 2) $V R=\frac{S}{r} \cdot \frac{H}{B}=s_{x} \cdot S \cdot \frac{H}{B}$

Where $H R$ and $V R$ are horizontal and vertical ground resolution respectively, $S$ is scale number, $r$ is image resolution, $s_{x}$ is pixel size, $H$ is flying height and $B$ is base distance between the stereo-images.

The precision of ground control measurements depends on the surveying technique used. For photoscales of 1/4,000-1/50,000 the use of differential GPS (dGPS) is recommended (Chandler, 1999). The precision of dGPS (stop and go, post processed) is typically in the 
order of 10-20 mm +1 ppm horizontally and 20-30 mm +1 ppm vertically (Uren and Price, 2006). When less precise ground data is used, such as topographical maps, these may introduce significant errors in the bundle adjustment.

\section{Accuracy}

Accuracy can be related to the presence of uncorrected systematic errors and other deficiencies in the functional model. Accounting for all unknown systematic effects in a selfcalibrating bundle adjustment is difficult because many cannot be modelled explicitly, and there is usually high correlation between the modelling parameters. Consequently, the mathematical model remains an approximation and provides a limiting constraint on the quality of derived data. Systematic errors may also arise from inaccurate or poorly distributed control points (Mills et al., 2003), which should be evenly distributed over the images to develop strong geometry, and ideally surround the volume of interest (Chandler, 1999). In theory only three points are required to define a datum, but in practice more control points are desirable as redundancy provides appropriate checks and allows a precision of the solution to be determined (Wolf and Dewitt, 2000).

The only way to quantify the accuracy of a photogrammetric solution is to compare calculated coordinates with accepted values. Traditionally, accuracy is evaluated by computing the global root-mean-square error (RMSE) of independent checkpoints. The combination of mean and standard deviation of error (ME and SDE) is more appropriate in a statistical sense ( $\mathrm{Li}$, 1988) and can be used to distinguish between the unwanted systematic errors (ME) and the expected and tolerable random effects (SDE) (Lane et al., 2003; Chandler et al., 2005).

\section{Reliability}

Reliability can be related to gross errors, and the ease with which they may be detected (Cooper and Cross, 1988). Gross errors are genuine mistakes or blunders that arise during photogrammetric measurement, for example misidentified or mistyped control points or mismatching in the process of automatic tie-point generation. Fortunately, gross errors are normally easy to detect and eradicate because of their size. Residuals of the control points in a bundle adjustment reflect the difference between measured and estimated values - large residuals indicate gross errors that can be interactively removed or corrected by the operator. Small gross errors that remain undetected will have a negative effect upon the accuracy of the derived data (Lane et al., 2003).

\section{Data-sets from two case-studies}

Photogrammetric techniques were applied in two case-studies, both concerning active landslides in the UK: the Mam Tor landslide in Hope Valley, Derbyshire (Ordnance Survey grid reference SK135835) and the East Pentwyn landslide in Ebbw Fach Valley, South Wales Coalfield (SO207075). Both landslides showed considerable movements over the last 50 years, were subject to frequent investigations in the past and are covered by a range of historical photography of varying quality. The working process adopted can be summarized in four general stages:

1. Search and acquisition of suitable imagery from archives (Figure 1)

2. Collection of precise ground control

3. Photogrammetric restitution and data extraction 
4. Visualization and analysis of the data

A range of data products was derived from the image sequences and explored for analysing geomorphological change occurring on the landslides. These products included geomorphological maps, 'DEMs of difference', displacement vectors (Figure 2) and animations. An extensive description of the case-studies is provided by Walstra et al. (2007).

(Figure 1)

(Figure 2)

\section{The datasets}

The photographic sequence acquired for the Mam Tor case-study comprised seven epochs, representing a variety of formats, scales, media and qualities (Figure 1 and Table 1). In general, camera parameters were readily available from calibration certificates and the photogrammetric restitution was straightforward. Only in the case of the MT-1953 and MT1971 epochs were calibration files lacking, and these had to be estimated in a self-calibrating bundle adjustment.

For the East Pentwyn case-study four epochs were acquired (Table 2). Calibrated camera parameters were available only for the EP-1971 images. Although the EP-1973 epoch was captured with a metric camera, a calibration certificate was lacking. The fiducial marks allowed an estimation of the principal point position, and values for the focal length and flying height were derived from the data strip displayed on the side of the frames. Selfcalibration did not lead to any significant improvements to the camera model, and so these rather crude parameter values had to be accepted. The RAF imagery (EP-1951 and EP-1955) presented a challenge because they exhibited large systematic distortions that could not be modelled; consequently an unsatisfactory camera model had to be adopted.

The achieved accuracies of the solutions are displayed in Table 3. It should be noted that the quoted errors are based on a limited number of checkpoints. The absence of systematic errors (except for EP-1955) is confirmed by insignificant ME values (relatively small compared to the SDE values) and validates the photogrammetric solutions, including the self-calibrating adjustments of MT-1953 and MT-1971. The large errors of the epochs EP-1951, EP-1955 and EP-1973 result from the inadequate camera model used, while the poor accuracy of MT-1953 can be attributed to the use of poor-quality scanned contact prints. The vertical accuracy is usually worse than horizontal, as is inherent to the geometry of standard aerial surveys (cf. Equation 2).

(Table 1)

(Table 2)

(Table 3)

Software and equipment

High-precision geodetic GPS receivers and differential methods were used for collecting ground control. For the Mam Tor case-study a combination of Leica system 200 and 300 
single frequency receivers was used for the surveying. For the other case-study a set of Leica system 500 dual frequency receivers was available. Control points were measured and post processed in a 'stop-and-go' type of survey, resulting in an accuracy of approximately $0.01 \mathrm{~m}$. Post-processing of the GPS data was performed by using Leica's SKI-Pro software, version 2.5.

All of the photogrammetric work described in this paper was processed on a moderately equipped PC using Leica Photogrammetry Suite (LPS) software, version 9, except for the self-calibration procedures, which were performed in the external General Adjustment Program (GAP) developed by Chandler and Clarke (1992). Statistical analyses were carried out using SPSS software, version 15.

\section{Error analysis}

As pointed out earlier, propagation of variance can be used to estimate the precision of derived parameters as a function of the original source data. This practice is crucial also to ensure an appropriate balance between the functional and stochastic models. The appropriateness of the stochastic model can be analysed by comparing the a priori value of the variance factor with the a posteriori value, which should be identical. Strictly comparison should be based on an F Test (Cooper, 1987), but in practice an a posteriori factor of 1-1.5 can be simply accepted at 0.05 levels of significance. A priori analysis allows a covariance matrix of the estimated parameters to be obtained, based on the statistical weights assigned to the measurements. This also allows an estimation of the precision of the estimated data. The $a$ posteriori variance factor is based on the actual residuals of the bundle adjustment, in relation to the assigned weightings. A significant difference (i.e. $>1.5$ ) between the two variance factors can be ascribed to a number of causes: errors in the computations, undetected systematic errors or blunders, inaccurate linearization of the functional model and/or a wrong stochastic model (Cooper, 1987).

The only global indicator for the quality of the adjustment provided by LPS is the 'total RMS error of solution'. This indicator does not relate to classical error theory described above, but is useful for the layperson, since it is derived from all residuals of the adjustment and expressed in image coordinate units, which is generally more meaningful to the user. In this study it was attempted to analyse the variance of the output data in a more rigorous way, principally in evaluating more fully the stochastic models used and identifying the main variables controlling data accuracy. Despite this rigour, it is recognised that this approach is based on rather limited datasets and is therefore inevitably speculative. Also, it was assumed that any gross errors in the bundle adjustment were successfully removed, and that all variance in the final data were solely due to random errors and perhaps small unresolved systematic errors.

A common measure of accuracy is the (root-) mean-square-error (MSE), defined as the sum of variances of random errors and bias (Equation 3) (Mikhail and Gracie, 1981).

(Equation 3) $M S E=\sigma^{2}+\beta^{2}$

Where $M S E$ is mean-square-error, $\sigma^{2}$ is a measure of the variance of random errors and $\beta^{2}$ represents the variance of bias (defined as the difference between mean value and true value). 
A simplified way of estimating the expected accuracy in a bundle adjustment would be by summing the contributed variances from both image and ground measurements, provided these are in the same coordinate system and units (Equation 4).

(Equation 4) $\Sigma \sigma^{2}=\sigma_{o}^{2}+\sigma_{i}^{2}$

Where $\Sigma \sigma^{2}$ is a measure of the total variance in the bundle adjustment, $\sigma_{o}^{2}$ is the variance of errors in object measurements, and $\sigma_{i}^{2}$ is the variance of errors in image measurements.

Equations 3 and 4 can be combined, and assuming the functional model is correct and systematic errors are absent $\left(\beta^{2}=0\right)$, it follows that the accuracy of the output data from the adjustment in theory should be directly related to the variance of the input measurements (Equation 5).

(Equation 5) $M S E=\sigma_{o}^{2}+\sigma_{i}^{2}$

Where $M S E$ is mean-square-error, $\sigma_{o}{ }^{2}$ is the variance of errors in object measurements, and $\sigma_{i}^{2}$ is the variance of errors in image measurements.

Random errors are introduced in the adjustment procedure as standard deviations ( $\sigma_{i}$ and $\sigma_{o}$ for image and ground measurements, respectively). In line with recommendations by LPS (i.e. use of values less than 1 pixel), initially, standard deviations of \pm 0.2 pixel were assigned to the image measurements (variable $a$ in the following analysis). These values were converted into object dimensions by multiplying them by the image ground resolution (Equations 6 and 7). Standard deviations of $0.01 \mathrm{~m}$ were assigned to the ground control measurements, based on the values from the GPS post-processing and already in object dimensions (variable $b$ in the following analysis; Equation 8). This latter contribution should be significant compared to the image ground resolution only in the case of very large-scale imagery (i.e. epoch MT1973).

(Equation 6) $\sigma_{i}(X, Y)=a \cdot H R$

(Equation 7) $\sigma_{i}(Z)=a \cdot V R$

(Equation 8) $\sigma_{o}(X, Y, Z)=b$

Where $\sigma_{i}(X, Y)$ and $\sigma_{i}(Z)$ are the standard deviations of image measurements in object dimensions, $\sigma_{o}(X, Y, Z)$ are the standard deviations of ground measurements, $a$ and $b$ are the weightings/precisions assigned to image and ground measurements, and $H R$ and $V R$ are the horizontal and vertical ground resolution of the stereo-pair (derived from Equations 1 and 2).

Substituting the values from Equations 6-8 into Equation 5 provided estimates of expected total variance, or MSE, of the bundle adjustment as a function of the input data (Equations 911). Since a single value for horizontal accuracy would be more useful than separate values for arbitrary $\mathrm{X}$ and $\mathrm{Y}$ directions (stereo-pairs from different epochs are not oriented to the same direction), these were combined through vector summation of $\sigma(X)$ and $\sigma(Y)$ (Equation 10).

(Equation 9) $\operatorname{MSE}(X, Y)=(a \cdot H R)^{2}+b^{2}$ 
(Equation 10) $\operatorname{MSE}($ Hor $)=2 \cdot \operatorname{MSE}(X, Y)=2 a^{2} \cdot H R^{2}+2 b^{2}$

(Equation 11) $\operatorname{MSE}(\mathrm{Ver})=(a \cdot V R)^{2}+b^{2}$

Where $\operatorname{MSE}(X, Y)$ is the variance in either $X$ or $Y$ direction, $M S E(H o r)$ is the combined horizontal variance, $M S E(V e r)$ is het vertical variance, $H R$ and $V R$ are horizontal and vertical ground resolution (derived from Equations 1 and 2), and $a$ and $b$ are the weightings assigned to image and ground measurements (initially set at 0.2 and 0.01 ).

The estimates of a priori expected accuracy (in terms of RMSE) of all epochs were compared to their corresponding a posteriori observed accuracy (in terms of SDE of checkpoints, from Table 3). With no exceptions, the observed errors were significantly larger than expected (Table 4). This suggests either the presence of unresolved systematic errors, or a significant underestimation of the random errors in the stochastic model. The first option can be dismissed judging from the insignificant mean errors observed (except for epochs EP-1951, EP-1955 and EP-1973, see Table 3), and anyway would be unlikely for the epochs with full camera calibration data available.

\section{(Table 4)}

The data were graphically displayed in order to look for any obvious trends (Figure 3), with epochs grouped according to their camera calibration status. Although the number of data points is little, at least for the epochs with fully calibrated camera models there seems to be a linear relation between expected and observed accuracy. However, its slope is much gentler than the ideal 1:1 line, suggesting that the stochastic model adopted was overoptimistic. For two epochs (MT-1953 and MT-1971) the camera model was successfully estimated through self-calibration, but some systematic errors may be left unresolved, perhaps due to the use of poor-quality prints, resulting in a steeper trend. The three other epochs, in which the camera model could not be resolved through self-calibration (EP-1973, EP-1951 and EP-1955), were left out in further analysis as they were considered outliers.

\section{(Figure 3)}

In order to find a better balance between expected and observed accuracy, it was explored how these uncertainties could be best reflected in the stochastic model,. Since $\sigma_{o}^{2}\left(=2 b^{2}\right)$ is constant for all epochs (same source for ground control), Equation 10 can be treated as a linear function between squared ground resolution and MSE. Assuming absence of systematic errors, MSE should equal the variance of the checkpoints (squared SDE values, derived from Table 3 ). The term $2 a^{2}$ corresponds to the slope of this linear relation and $2 b^{2}$ to the intercept. For the group of fully-calibrated epochs these terms were determined through regression (Figure 4) and provided optimum values for the weighting parameters $a$ and $b$ (respectively 0.82 and 0.20 instead of the initially used 0.2 and 0.01 ).

The data-points of the two self-calibrated, poorly scanned epochs are situated beyond this line (Figure 4), even if much more so for epoch MT-1953 than for MT-1971. In an attempt to account for the additional errors inherent to using low-quality scanned prints, a similar regression was carried out for this 'group' of points. Since the same ground control was used, the precision in the object measurements was assumed identical; hence the intercept should be the same as for the fully calibrated cameras. In this case, regression revealed a value of 2.55 for weighting parameter $a$. 
(Figure 4)

\section{Testing image measurement precision}

The discrepancy between the initially assigned weighting parameters and the optimised values suggest an underestimation of the errors in the image and/or ground measurements. Especially the sub-pixel precision of image measurements seems a little too optimistic. Such a precision may be feasible using artificial targets in a controlled photogrammetric network, but is clearly unrealistic for the natural objects used as ground control in this study.

The only way to obtain a reliable estimate of 'true' precision is to obtain repeat measurements and analyse the standard deviations of errors (Mikhail and Gracie, 1981). For this purpose, a small subset of five control points was repeatedly measured on two individual photographs from different epochs (MT-1953 and MT-1973). The points represent natural features typically used for ground control and were actually used in the Mam Tor case-study. In this experiment, each of the points was measured ten times on both images, in order to derive a statistically valid dataset (i.e. with a precision of less than one standard deviation at the 0.01 level of significance). This procedure was completed by six different operators, including three photogrammetric experts and three 'non-experts'.

\section{(Table 5)}

(Table 6)

\section{(Figure 5)}

From the statistics (Tables 5 and 6) a number of conclusions can be drawn. First of all, the standard errors of almost all measured points were considerably larger than 0.2 of a pixel. There was a certain variation in standard errors between points, as well as between images and between operators. The standard deviations of measurements 'within' operators (last column) were computed by averaging the variances of all points for each operator. They reflect the ability to repeatedly identify the same image point and strongly depend on the distinctiveness and contrast of objects in the image, as well as on the operator's skills (although no clear distinction could be made between the performance of experts and 'nonexperts'). These errors correspond to the random errors inherent to any measurement procedure. Standard errors 'within' each operator ranged from 0.28-1.05 pixel for the MT1953 image and 0.64-4.53 for the MT-1973 image. On the other hand, the standard deviations of measurements 'between' operators (lower rows), derived from combining measurements from all operators for each point, appeared to be significantly larger - ranging from 0.40-3.60 pixel for the MT-1953 image and 0.90-15.43 for the MT-1973 image. Such large errors clearly indicated discrepancies between operators in correlating ground features to their 'correct' image point, reflected in an offset between the estimated (mean) locations (and hence potentially from their 'true' location). A clear example of such 'misidentification' is illustrated by the measurements of point 2 in image MT-1973, with two point clouds distinctively separate from the rest (Figure 5: operators A1 and B3). Normally such incorrect measurements would be easily detected as gross errors and removed from the adjustment. In other cases, such 'misidentifications' may be very subtle and hardly separable from random measurement errors, thereby reducing the effective accuracy of the solution. An example of 
such subtle 'misidentification' is illustrated by the measurements of point 2 in image MT1953, showing slightly off-set but still largely overlapping point clouds (Figure 5). On the other hand, point 4 in image MT-1953 represents an excellent control point with perfectly overlapping point clouds and standard errors 'within' and 'between' operators of comparable size.

\section{Discussion}

\section{Effects of 'misidentification' errors}

The image measurement experiment demonstrated that standard errors are considerably larger when dealing with natural objects, than the values routinely used in the stochastic models. Indeed, this confirms the use of larger weightings for image measurements in bundle adjustments as suggested by the error analysis in this study.

But, interestingly, the measurements from the poor quality image MT-1953 showed more consistency than the better quality image MT-1973 (Table 5: overall SDE of 1.65 and 1.84 in $\mathrm{x} / \mathrm{y}$ versus 5.34 and 8.45). At first sight, this seems contrary to the accuracies observed in the photogrammetric solutions of the two epochs (Table 3) and the subsequent argumentation in this study which culminated in the assignment of larger weightings to the measurements from poor quality imagery. A possible explanation would be that the effect of 'misidentification' of image points is linked to image scale rather than directly proportional to pixel size. The exact identification of a large object (e.g. the corner of a wall) may cause more trouble in the case of larger-scale imagery, where the object extends over multiple pixels and thereby increasing the chance and size (in pixel units) of 'misidentification'. As such, it can be argued that the effect of 'misidentification' should be reflected in the weightings of ground rather than image measurements, so that their effect becomes relatively greater for larger-scale imagery. It also explains the initially poor ratio between observed and expected accuracy of the MT-1973 epoch (Table 4).

Random errors are inherent to the (radiometric) quality of the available imagery, but the effect of 'misidentifications' can only be reduced by selecting appropriate objects for ground control. Suitable control points should be well-defined and undisputable features, both in the field and on the imagery. Of course, if historical imagery is used, problems of accessibility and site changes may limit the choice. And even if features seem appropriate for one pair of images, this may be different for another (Figure 5: compare point 4 in MT-1953 and MT1971).

\section{Controls on data quality}

Apart from improvements to the stochastic model, Equations 10 and 11 also provide a means to estimate the accuracy of coordinated points a priori, based on scanning resolution and image scale. Furthermore, the analysis showed that the accuracy that can be achieved from scanned prints may be up to a factor $3.1(2.55 / 0.82)$ worse than scanned diapositives. Of course this value is of limited significance, since it is based on very limited data, but it gives an indication of the degenerating effect on accuracy, when poor-quality source material is used. 
Other factors that may affect data accuracy include the amount and distribution of control points, and the quality of camera calibration data. Although the datasets in this study were too limited to quantify all of these factors, an attempt to relate their effects is presented in Figure 6 (the scale bar provided is only a rough estimate). The top of this diagram represents the best data quality that can be achieved using high-quality scanned contact-diapositives, a calibrated metric camera model and high quality control data. The quality of source data degrades down to the bottom of the diagram, with the worst results to expect from paper prints scanned with a cheap desktop device (a factor of 3.1 compared to top quality). Regarding camera calibration, still reasonable results can be achieved when the camera geometry is estimated in a selfcalibrating procedure, although this would strongly depend on the availability of high quality ground control. Ground control will be a limiting factor when its accuracy is low compared to the image ground resolution or when its spatial distribution within the images is poor.

A more global factor for long-term stability of the photographic record could also be considered in such analysis. Such a term would incorporate different effects such as camera and film quality, and reliability of ground control (i.e. did control points really remain unchanged). These factors all deteriorate with increasing age but their effects are difficult to separate and quantify.

\section{Figure 6.}

\section{Conclusion}

The aim of this study was to evaluate the controls on photogrammetric data quality in the context of archival (film) imagery, typically used in geomorphological studies. Systematic analysis showed that uncertainties associated with image measurements of natural objects are larger than the values routinely used and accepted for appropriately controlled and targeted photogrammetric networks. Limited distinctiveness and contrast of the objects aversely affect the size of random errors, while small 'misidentifications' may lead to undetected gross errors. It is suggested that the effects of such 'misidentifications' should be reflected in the standard deviations assigned to ground rather than image measurements in the adjustment.

Based on a variety of source data used in two case-studies, optimised weighting factors for the stochastic model were estimated, which appeared significantly larger than previously used values: a standard error of 0.82 of a pixel for image measurements and $0.20 \mathrm{~m}$ for dGPS ground control measurements. The analysis also showed that the data accuracy from scanned prints may be up to 3.1 times worse than from photogrammetric-quality scanned diapositives. Using these insights, accuracy of derived data can now be estimated a priori and its suitability judged, based on the characteristics of the imagery.

\section{Acknowledgements}

Most of the work described in this paper was carried out at the Department of Civil and Building Engineering, Loughborough University, and formed part of the lead author's doctoral thesis (available online: Walstra, 2006). 'Non-expert' colleagues from Ghent (Meins Coetsier, Guido Suurmeijer and Peter Verkinderen) are thanked for participating in the image measurements. Two anonymous reviewers are thanked for valuable comments on an earlier draft of this paper. 


\section{Bibliography}

Baily, B., Collier, P., Farres, P. J., Inkpen, R., Pearson, A., 2003. Comparative assessment of analytical and digital photogrammetric methods in the construction of DEMs of geomorphological forms. Earth Surface Processes and Landforms, 28 (3), pp. 307-320.

Baltsavias, E. P., 1999. On the performance of photogrammetric scanners. Photogrammetric Week '99, Stuttgart, Germany, pp. 155-173.

Brown, D. C., 1956. The Simultaneous Determination of the Orientation and Lens Distortion of a Photogrammetric Camera. RCA Data Reduction Technical Report No. 33. ASTIA, Document no. 96626.

Butler, J. B., Lane, S. N., Chandler, J. H., 1998. Assessment of DEM quality for characterizing surface roughness using close range digital photogrammetry. Photogrammetric Record, 16 (92), pp. 271-291.

Chandler, J. H., 1999. Effective application of automated digital photogrammetry for geomorphological research. Earth Surface Processes and Landforms, 24 (1), pp. 51-63.

Chandler, J. H., Clarke, J. S., 1992. The archival photogrammetric technique: further application and development. Photogrammetric Record, 14 (80), pp. 241-247.

Chandler, J. H., Cooper, M. A. R., 1989. The extraction of positional data from historical photographs and their application to geomorphology. Photogrammetric Record, 13 (73), pp. 69-78.

Chandler, J. H., Fryer, J. G., Jack, A., 2005. Metric capabilities of low-cost digital cameras for close range surface measurement. Photogrammetric Record, 20 (109), pp. 12-26.

Cooper, M. A. R., 1987. Control surveys in civil engineering. Collins, London, UK.

Cooper, M. A. R., 1998. Datums, coordinates and differences. In: Lane, S. N., Richards, D. J., Chandler, J. H. (Eds.) Landform monitoring, modelling and analysis. Wiley, Chichester, UK, pp. 21-36.

Cooper, M. A. R., Cross, P. A., 1988. Statistical concepts and their application in photogrammetry and surveying. Photogrammetric Record, 12 (71), pp. 637-663.

Cramer, M., 2005. Digital airborne cameras: status and future. ISPRS Workshop on HighResolution Earth Imaging for Geospatial Information,17-20 May 2005, Hanover, Germany, 8 pp.

Fraser, C. S., 1984. Network Design Considerations for Non-Topographic Photogrammetry. Photogrammetric Engineering \& Remote Sensing, 50 (8), pp. 1115-1126. 
Fraser, C. S., 2007. Structural monitoring. In: Fryer, J. G., Mitchell, H. L., Chandler, J. H. (Eds.) Applications of 3D measurement from images. Whittles, Caithness, Scotland, pp. 3764.

Fryer, J. G., Chandler, J. H., Cooper, M. A. R., 1994. On the accuracy of heighting from aerial photographs and maps: implications to process modellers. Earth Surface Processes and Landforms, 19 (6), pp. 577-583.

Granshaw, S. I., 1980. Bundle adjustment methods in engineering photogrammetry. Photogrammetric Record, 10 (56), pp. 181-207.

Jacobsen, K., 1998. Block Adjustment (Internal Report). Institut für Photogrammetrie und GeoInformation, Hanover, Germany. Online at http://www.ipi.unihannover.de/uploads/tx_tkpublikationen/block_adjustment.pdf [accessed 30/9/2010].

Kenefick, J. F., Gyer, M. S., Harp, B. F., 1972. Analytical Self-Calibration. Photogrammetric Engineering, 38 (11), pp. 1117-1126.

Lane, S. N., James, T. D., Crowell, M. D., 2000. Application of digital photogrammetry to complex topography for geomorphological research. Photogrammetric Record, 16 (95), pp. 793-821.

Lane, S. N., Richards, K. S., Chandler, J. H., 1993. Developments in photogrammetry; the geomorphological potential. Progress in Physical Geography, 17, pp. 306-328.

Lane, S. N., Westaway, R. M., Hicks, D. M., 2003. Estimation of erosion and deposition volumes in a large, gravel-bed, braided river using synoptic remote sensing. Earth Surface Processes and Landforms, 28, pp. 249-271.

Li, Z., 1988. On the measure of digital terrain model accuracy. Photogrammetric Record, 12 (72), pp. 873-877.

Lillesand, T. M., Kiefer, R. W., 1994. Remote sensing and image interpretation. John Wiley $\&$ Sons, New York.

Lo, C. P., 1976. Geographical applications of aerial photography. David \& Charles, Newton Abbot, UK.

Mikhail, E. M., Gracie, G., 1981. Analysis and adjustment of survey measurements. Van Nostrand Reinhold Company, New York.

Mills, J. P., Buckley, S. J., Mitchell, H. L., 2003. Synergistic Fusion of GPS and Photogrammetrically Generated Elevation Models. Photogrammetric Engineering \& Remote Sensing, 69 (4), pp. 341-349.

NAPLIB, 1999. Directory of Aerial Photographic Collections in the United Kingdom (2nd edition).

Petrie, G., Walker, A. S., 2007. Airborne digital imaging technology: a new overview. The Photogrammetric Record, 22 (119), pp. 203-225. 
Schenk, A. F., 1996. Automatic Generation of DEM's. In: Cary, T., Jensen, J., Nyquist, M. (Eds.) Digital Photogrammetry. An addendum to the Manual of Photogrammetry. American Society for Photogrammetry and Remote Sensing, Bethesda, Maryland, pp. 247-250.

Slama, C. C., 1980. The manual of photogrammetry (4th edition). American Society for Photogrammetry, Falls Church, Virginia.

Thomson, G., 2010. Digital camera performance where spatial resolution is determined by the optical component. The Photogrammetric Record, 25 (129), pp. 42-46.

Uren, J., Price, W. F., 2006. Surveying for engineers. Palgrave Macmillan, Basingstoke/New York.

USGS, 1997. Looking for an Old Aerial Photograph. Fact Sheet 127-96. Online at http://egsc.usgs.gov/isb/pubs/factsheets/fs12796.pdf [accessed 30/9/2010].

Walstra, J., 2006. Historical aerial photographs and digital photogrammetry for landslide assessment. Ph.D. thesis, Loughborough University. Online at http://hdl.handle.net/2134/2501 [accessed 30/9/2010].

Walstra, J., Dixon, N., Chandler, J. H., 2007. Historical aerial photographs for landslide assessment: two case histories. Quarterly Journal of Engineering Geology and Hydrogeology, 40 (4), pp. 315-332.

Wolf, P. R., Dewitt, B. A., 2000. Elements of Photogrammetry. With Applications in GIS. McGraw-Hill, Boston, Massachusetts. 
Table 1. Characteristics of the acquired photographic records for the Mam Tor (MT) case-study.

\begin{tabular}{|c|c|c|c|c|c|c|c|c|c|}
\hline Epoch & source & scale & focal length & $\mathrm{B} / \mathrm{H}$ ratio & $\begin{array}{l}\text { scan } \\
\text { resolution }\end{array}$ & $\begin{array}{l}\text { ground } \\
\text { resolution }\end{array}$ & image type & format & original media \\
\hline MT-1953 & NMR & $1 / 10,700$ & $547 \mathrm{~mm}^{*}$ & $1 / 8.0$ & $42 \mu \mathrm{m}$ & $0.45 \mathrm{~m}$ & $\mathrm{~B} / \mathrm{W}$ vertical & $18 \times 21 \mathrm{~cm}$ & contact prints \\
\hline MT-1971 & NMR & $1 / 6,400$ & 304 mm* & $1 / 3.4$ & $42 \mu \mathrm{m}$ & $0.27 \mathrm{~m}$ & $\mathrm{~B} / \mathrm{W}$ vertical & $23 \times 23 \mathrm{~cm}$ & contact prints \\
\hline МТ-1973 & CUCAP & $1 / 4,300$ & $153 \mathrm{~mm}$ & $1 / 2.5$ & $15 \mu \mathrm{m}$ & $0.065 \mathrm{~m}$ & $\mathrm{~B} / \mathrm{W}$ vertical & $23 \times 23 \mathrm{~cm}$ & diapositives \\
\hline MT-1984 & ADAS & $1 / 27,200$ & $152 \mathrm{~mm}$ & $1 / 1.7$ & $15 \mu \mathrm{m}$ & $0.41 \mathrm{~m}$ & $\mathrm{~B} / \mathrm{W}$ vertical & $23 \times 23 \mathrm{~cm}$ & diapositives \\
\hline MT-1990 & CUCAP & $1 / 12,000$ & $153 \mathrm{~mm}$ & $1 / 1.8$ & $15 \mu \mathrm{m}$ & $0.18 \mathrm{~m}$ & $\mathrm{~B} / \mathrm{W}$ vertical & $23 \times 23 \mathrm{~cm}$ & diapositives \\
\hline MT-1995 & CUCAP & $1 / 16,400$ & $152 \mathrm{~mm}$ & $1 / 1.9$ & $15 \mu \mathrm{m}$ & $0.25 \mathrm{~m}$ & colour vertical & $23 \times 23 \mathrm{~cm}$ & negatives \\
\hline MT-1999 & Infoterra & $1 / 12,200$ & $153 \mathrm{~mm}$ & $1 / 1.9$ & $21 \mu \mathrm{m}$ & $0.26 \mathrm{~m}$ & colour vertical & $23 \times 23 \mathrm{~cm}$ & negatives \\
\hline
\end{tabular}

NMR $=$ National Monuments Record

CUCAP = Cambridge University Collection of Aerial Photographs

ADAS = Agricultural Development and Advisory Service

$\mathrm{B} / \mathrm{W}=$ black-and-white photographs

$*$ = estimated values from self-calibration 
Table 2. Characteristics of the acquired photographic records for the East Pentwyn (EP) case-study.

\begin{tabular}{|c|c|c|c|c|c|c|c|c|c|}
\hline Epoch & source & scale & focal length & $\mathrm{B} / \mathrm{H}$ ratio & $\begin{array}{l}\text { scan } \\
\text { resolution }\end{array}$ & $\begin{array}{l}\text { ground } \\
\text { resolution }\end{array}$ & image type & format & original media \\
\hline EP-1951 & CRAPW & $1 / 9,800$ & $508 \mathrm{~mm} *$ & $1 / 6.8$ & $14 \mu \mathrm{m}$ & $0.14 \mathrm{~m}$ & $\mathrm{~B} / \mathrm{W}$ vertical & $18 \times 21 \mathrm{~cm}$ & diapositives \\
\hline EP-1955 & CRAPW & $1 / 9,200$ & $508 \mathrm{~mm}^{*}$ & $1 / 7.6$ & $14 \mu \mathrm{m}$ & $0.13 \mathrm{~m}$ & $\mathrm{~B} / \mathrm{W}$ vertical & $18 \times 21 \mathrm{~cm}$ & diapositives \\
\hline EP-1971 & Fugro-BKS & $1 / 13,000$ & $153 \mathrm{~mm}^{*}$ & $1 / 1.9$ & $14 \mu \mathrm{m}$ & $0.18 \mathrm{~m}$ & $\mathrm{~B} / \mathrm{W}$ vertical & $23 \times 23 \mathrm{~cm}$ & diapositives \\
\hline EP-1973 & CRAPW & $1 / 8,000$ & $152 \mathrm{~mm}$ & $1 / 1.7$ & $16 \mu \mathrm{m}$ & $0.13 \mathrm{~m}$ & $\mathrm{~B} / \mathrm{W}$ vertical & $23 \times 23 \mathrm{~cm}$ & diapositives \\
\hline
\end{tabular}

CRAPW $=$ Central Register of Air Photography for Wales

Fugro-BKS = formerly BKS Surveys

$\mathrm{B} / \mathrm{W}=$ black-and-white photographs

$*$ = estimated values from auxiliary data 
Table 3. Achieved accuracies of the photogrammetric solutions, assessed by independent checkpoints and expressed in terms of mean error (ME) and standard deviation of error (SDE).

\begin{tabular}{|c|c|c|c|c|c|c|c|c|c|}
\hline \multirow[t]{2}{*}{ Epoch } & \multirow[t]{2}{*}{$\begin{array}{l}\text { number of } \\
\text { checkpoints }\end{array}$} & \multicolumn{8}{|c|}{ accuracy of photogrammetric model in object space $(\mathrm{m})$} \\
\hline & & \multicolumn{2}{|l|}{$\mathrm{X}$} & \multicolumn{2}{|l|}{ Y } & \multicolumn{2}{|l|}{ Hor } & \multicolumn{2}{|l|}{$\mathrm{Z}$} \\
\hline MT-1953 & 4 & -0.07 & 0.63 & 0.23 & 1.60 & 0.24 & 1.71 & -0.42 & 4.84 \\
\hline MT-1971 & 5 & 0.03 & 0.52 & 0.29 & 0.34 & 0.29 & 0.62 & -0.82 & 0.99 \\
\hline MT-1984 & 5 & -0.30 & 0.37 & 0.18 & 0.40 & 0.35 & 0.55 & 1.17 & 1.37 \\
\hline MT-1990 & 6 & -0.12 & 0.25 & 0.27 & 0.32 & 0.29 & 0.41 & 0.07 & 0.45 \\
\hline MT-1995 & 6 & -0.12 & 0.36 & 0.04 & 0.26 & 0.13 & 0.44 & -0.26 & 0.49 \\
\hline МТ-1999 & 5 & -0.21 & 0.17 & -0.08 & 0.32 & 0.22 & 0.37 & 0.15 & 0.88 \\
\hline EP-1973 & 2 & 0.45 & 1.05 & -0.06 & 0.41 & 0.46 & 1.13 & 1.23 & 2.07 \\
\hline
\end{tabular}


Table 4. Comparison between expected (RMSE) and observed accuracy (SDE); note that RMSE(X,Y) represents accuracy in either X or Y, whereas RMSE(Hor) is the summed error of both.

\begin{tabular}{|c|c|c|c|c|c|c|c|c|c|}
\hline \multirow[t]{2}{*}{ Epoch } & \multicolumn{3}{|c|}{ expected accuracy (m) } & \multicolumn{4}{|c|}{ observed accuracy (m) } & \multicolumn{2}{|c|}{ observed/expected accuracy } \\
\hline & RMSE (X, Y) & RMSE (Hor) & RMSE (Z) & $\operatorname{SDE}(\mathrm{X})$ & $\operatorname{SDE}(\mathrm{Y})$ & SDE (Hor) & $\operatorname{SDE}(Z)$ & ratio (Hor) & ratio $(\mathrm{Z})$ \\
\hline MT-1953 & 0.090 & 0.128 & 0.719 & 0.63 & 1.60 & 1.71 & 4.84 & 13,40 & 6,73 \\
\hline MT-1971 & 0.055 & 0.077 & 0.183 & 0.52 & 0.34 & 0.62 & 0.99 & 8,04 & 5,42 \\
\hline MT-1973 & 0.016 & 0.023 & 0.034 & 0.09 & 0.22 & 0.24 & 0.59 & 10,39 & 17,33 \\
\hline MT-1984 & 0.082 & 0.116 & 0.139 & 0.37 & 0.40 & 0.55 & 1.37 & 4,71 & 9,82 \\
\hline MT-1990 & 0.037 & 0.053 & 0.066 & 0.25 & 0.32 & 0.41 & 0.45 & 7,78 & 6,81 \\
\hline MT-1995 & 0.050 & 0.071 & 0.094 & 0.36 & 0.26 & 0.44 & 0.49 & 6,23 & 5,17 \\
\hline MT-1999 & 0.052 & 0.074 & 0.098 & 0.17 & 0.32 & 0.37 & 0.88 & 4,98 & 9,01 \\
\hline EP-1951 & 0.029 & 0.041 & 0.187 & 1.72 & 1.21 & 2.11 & 8.69 & 50,98 & 46,51 \\
\hline EP-1955 & 0.028 & 0.039 & 0.196 & 1.34 & 1.08 & 1.72 & 3.96 & 44,09 & 20,18 \\
\hline EP-1971 & 0.038 & 0.053 & 0.070 & 0.20 & 0.26 & 0.33 & 0.82 & 6,10 & 11,68 \\
\hline EP-1973 & 0.027 & 0.039 & 0.045 & 1.05 & 0.41 & 1.13 & 2.07 & 28,95 & 46,45 \\
\hline
\end{tabular}


Table 5. Standard deviations of image measurements of five different objects on the MT-1953 image by six different operators (experts: A1, A2, A3; 'non-experts': B1, B2, B3). Units are in pixels.

\begin{tabular}{|c|c|c|c|c|c|c|c|}
\hline Operator & & $\begin{array}{c}1 \\
\text { Shed corner }\end{array}$ & $\begin{array}{c}2 \\
\text { Farm house } \\
\text { corner }\end{array}$ & $\begin{array}{c}3 \\
\text { Shed corner }\end{array}$ & $\begin{array}{c}4 \\
\begin{array}{c}\text { Intersection of } \\
\text { walls }\end{array} \\
\end{array}$ & $\begin{array}{c}5 \\
\text { Shed corner }\end{array}$ & $\begin{array}{c}\text { All } \\
\text { ('within' } \\
\text { operator) }\end{array}$ \\
\hline \multirow[t]{2}{*}{ A1 } & $\mathrm{X}$ & 0.26 & 0.26 & 0.54 & 0.27 & 1.22 & 0.63 \\
\hline & $\mathrm{y}$ & 0.42 & 0.49 & 0.29 & 0.26 & 1.10 & 0.60 \\
\hline \multirow[t]{2}{*}{$\mathrm{A} 2$} & $\mathrm{x}$ & 0.33 & 1.08 & 0.59 & 0.56 & 1.65 & 0.97 \\
\hline & $\mathrm{y}$ & 0.62 & 1.41 & 0.65 & 0.28 & 1.64 & 1.05 \\
\hline \multirow[t]{2}{*}{$\mathrm{A} 3$} & $\mathrm{x}$ & 0.25 & 0.09 & 0.41 & 0.20 & 0.32 & 0.28 \\
\hline & $\mathrm{y}$ & 0.31 & 0.36 & 0.31 & 0.18 & 0.21 & 0.28 \\
\hline \multirow[t]{2}{*}{ B1 } & $\mathrm{x}$ & 0.36 & 0.71 & 0.61 & 0.32 & 0.82 & 0.60 \\
\hline & $\mathrm{y}$ & 0.17 & 0.85 & 0.49 & 0.25 & 0.25 & 0.47 \\
\hline \multirow[t]{2}{*}{$\mathrm{B} 2$} & $\mathrm{x}$ & 0.18 & 0.93 & 0.52 & 0.51 & 0.90 & 0.67 \\
\hline & $\mathrm{y}$ & 0.39 & 1.36 & 0.45 & 0.31 & 0.92 & 0.79 \\
\hline \multirow[t]{2}{*}{ B3 } & $\mathrm{x}$ & 0.62 & 1.33 & 1.00 & 0.90 & 1.23 & 1.05 \\
\hline & $\mathrm{y}$ & 0.57 & 0.57 & 0.77 & 0.65 & 0.44 & 0.61 \\
\hline \multirow{2}{*}{$\begin{array}{l}\text { All } \\
\text { ('between' operator) }\end{array}$} & $\mathrm{x}$ & 0.99 & 1.76 & 1.03 & 0.54 & 2.86 & 1.65 \\
\hline & $\mathrm{y}$ & 0.59 & 1.69 & 0.79 & 0.40 & 3.60 & 1.84 \\
\hline Covariance & & $-0.204 *$ & $-1.679 *$ & $-0.580 *$ & 0.034 & $-6.700 *$ & \\
\hline
\end{tabular}

* Correlation $\mathrm{x}$-y is significant at the 0.01 level (2-tailed) 
Table 6. Standard deviations of image measurements of five different objects on the MT-1973 image by six different operators (experts: A1, A2, A3; 'non-experts': B1, B2, B3). Units are in pixels.

\begin{tabular}{|c|c|c|c|c|c|c|c|}
\hline Operator & & $\begin{array}{c}1 \\
\text { Shed corner }\end{array}$ & $\begin{array}{c}2 \\
\text { Farm house } \\
\text { corner }\end{array}$ & $\begin{array}{c}3 \\
\text { Shed corner }\end{array}$ & $\begin{array}{c}4 \\
\begin{array}{c}\text { Intersection of } \\
\text { walls }\end{array} \\
\end{array}$ & $\begin{array}{c}5 \\
\text { Shed corner }\end{array}$ & $\begin{array}{c}\text { All } \\
\text { ('within' } \\
\text { operator) }\end{array}$ \\
\hline \multirow[t]{2}{*}{ A1 } & $\mathrm{x}$ & 0.86 & 1.75 & 0.97 & 0.61 & 1.42 & 1.19 \\
\hline & $\mathrm{y}$ & 1.82 & 0.94 & 1.89 & 0.73 & 1.70 & 1.50 \\
\hline \multirow[t]{2}{*}{ A2 } & $\mathrm{x}$ & 0.96 & 1.56 & 1.28 & 1.47 & 3.36 & 1.92 \\
\hline & $\mathrm{y}$ & 1.37 & 1.95 & 1.19 & 1.40 & 1.48 & 1.50 \\
\hline \multirow[t]{2}{*}{$\mathrm{A} 3$} & $\mathrm{x}$ & 1.46 & 0.47 & 0.79 & 0.36 & 0.65 & 0.84 \\
\hline & $\mathrm{y}$ & 2.25 & 0.45 & 0.47 & 0.64 & 0.52 & 1.11 \\
\hline \multirow[t]{2}{*}{ B1 } & $\mathrm{x}$ & 0.67 & 0.67 & 0.90 & 0.29 & 0.51 & 0.64 \\
\hline & $\mathrm{y}$ & 1.35 & 0.45 & 0.55 & 0.61 & 0.32 & 0.75 \\
\hline \multirow[t]{2}{*}{ B2 } & $\mathrm{x}$ & 2.10 & 1.91 & 0.98 & 0.77 & 2.53 & 1.79 \\
\hline & $\mathrm{y}$ & 2.99 & 1.52 & 0.36 & 4.54 & 1.79 & 2.65 \\
\hline \multirow[t]{2}{*}{ B3 } & $\mathrm{x}$ & 0.63 & 2.44 & 5.65 & 0.64 & 1.32 & 2.84 \\
\hline & $\mathrm{y}$ & 0.94 & 4.35 & 8.66 & 2.34 & 1.51 & 4.53 \\
\hline \multirow{2}{*}{$\begin{array}{l}\text { All } \\
\text { ('between' operator) }\end{array}$} & $\mathrm{x}$ & 2.05 & 15.43 & 4.33 & 0.90 & 9.75 & 8.45 \\
\hline & $\mathrm{y}$ & 2.85 & 7.60 & 4.27 & 5.25 & 5.54 & 5.34 \\
\hline Covariance & & $-4.756^{*}$ & $58.880^{*}$ & $-12.833^{*}$ & $-2.196 *$ & $-49.986^{*}$ & \\
\hline
\end{tabular}

* Correlation $\mathrm{x}$-y is significant at the 0.01 level (2-tailed) 

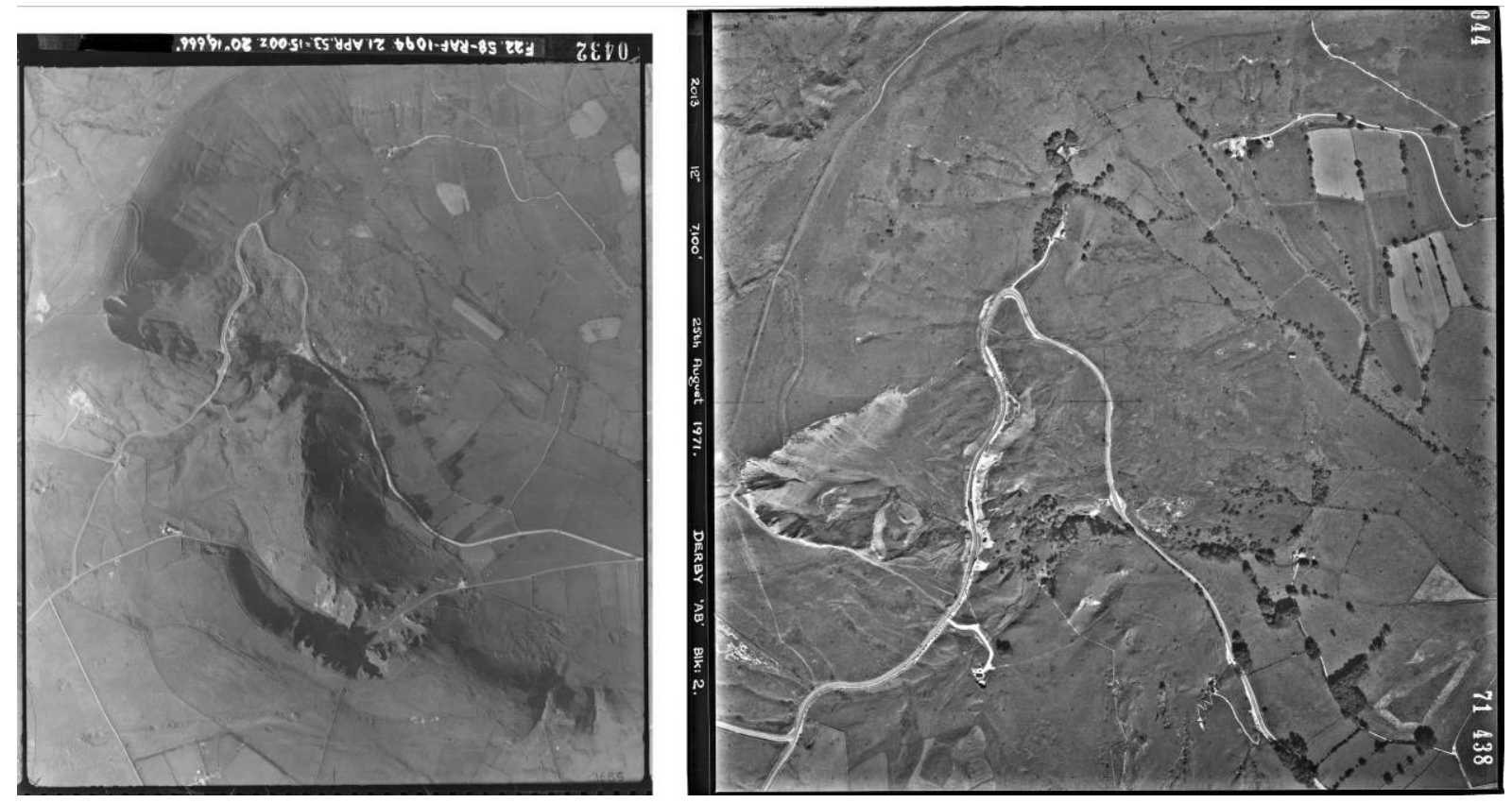

Figure 1. Typical examples of historical photographs used in the case-study of Mam Tor: left image is a RAF airphoto acquired in 1953, right image was taken by Ordnance Survey in 1971 (@ Crown copyright Ordnance Survey. All rights reserved).These examples clearly illustrate that the available material does not always meet the ideal qualities for photogrammetric analysis: The RAF image was taken from great height and is hazy, while both images are rather poor quality scanned contact-prints (North is up). 


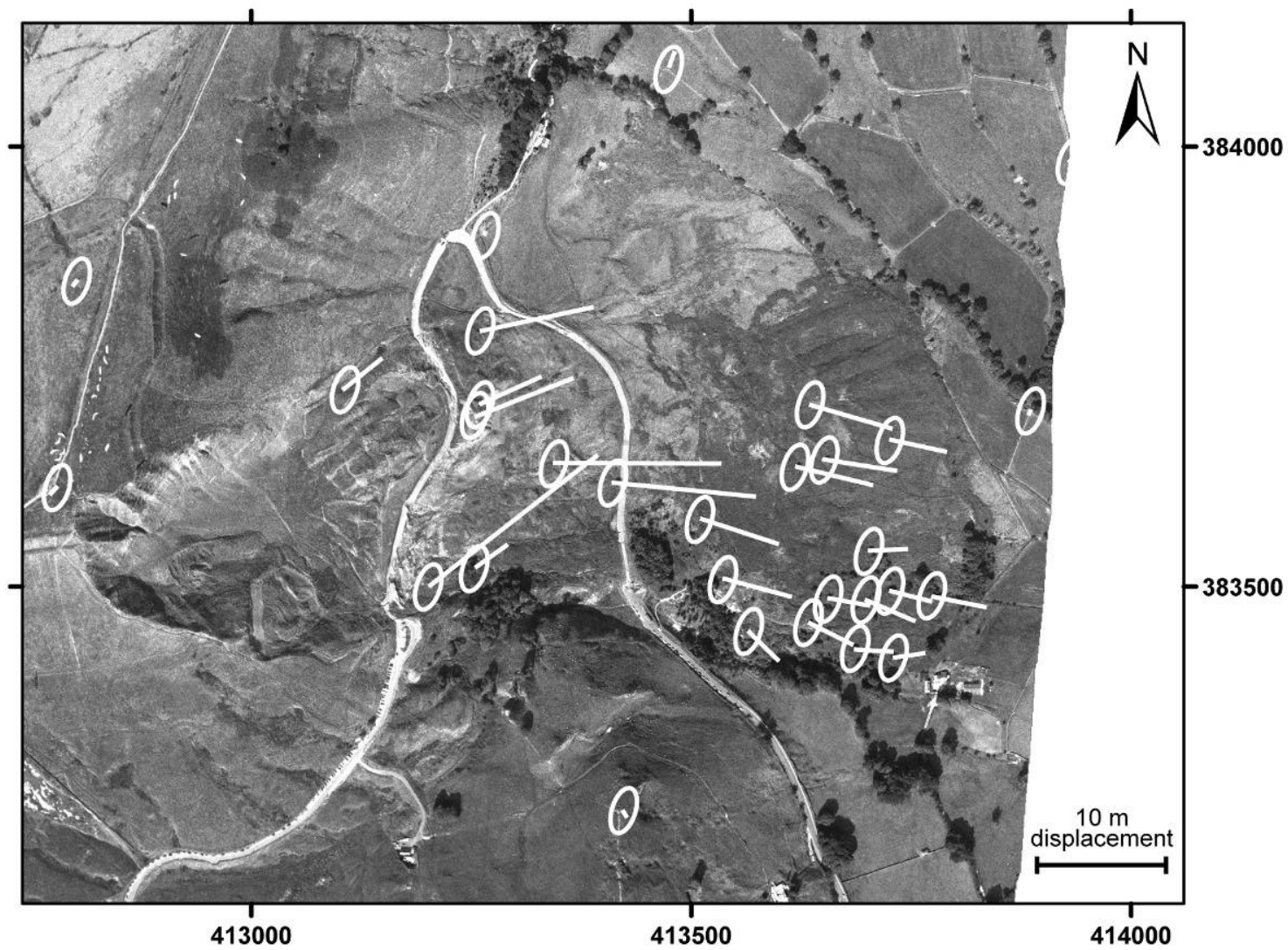

Figure 2. Horizontal displacement vectors of the Mam Tor landslide, obtained through repeated measurement of natural surface objects from the 1973 and 1999 image epochs. Background image is an orthophoto created from the 1999 imagery. The error ellipses represent the 0.05 level of significance, scale of vectors is $15 x$ image scale. 


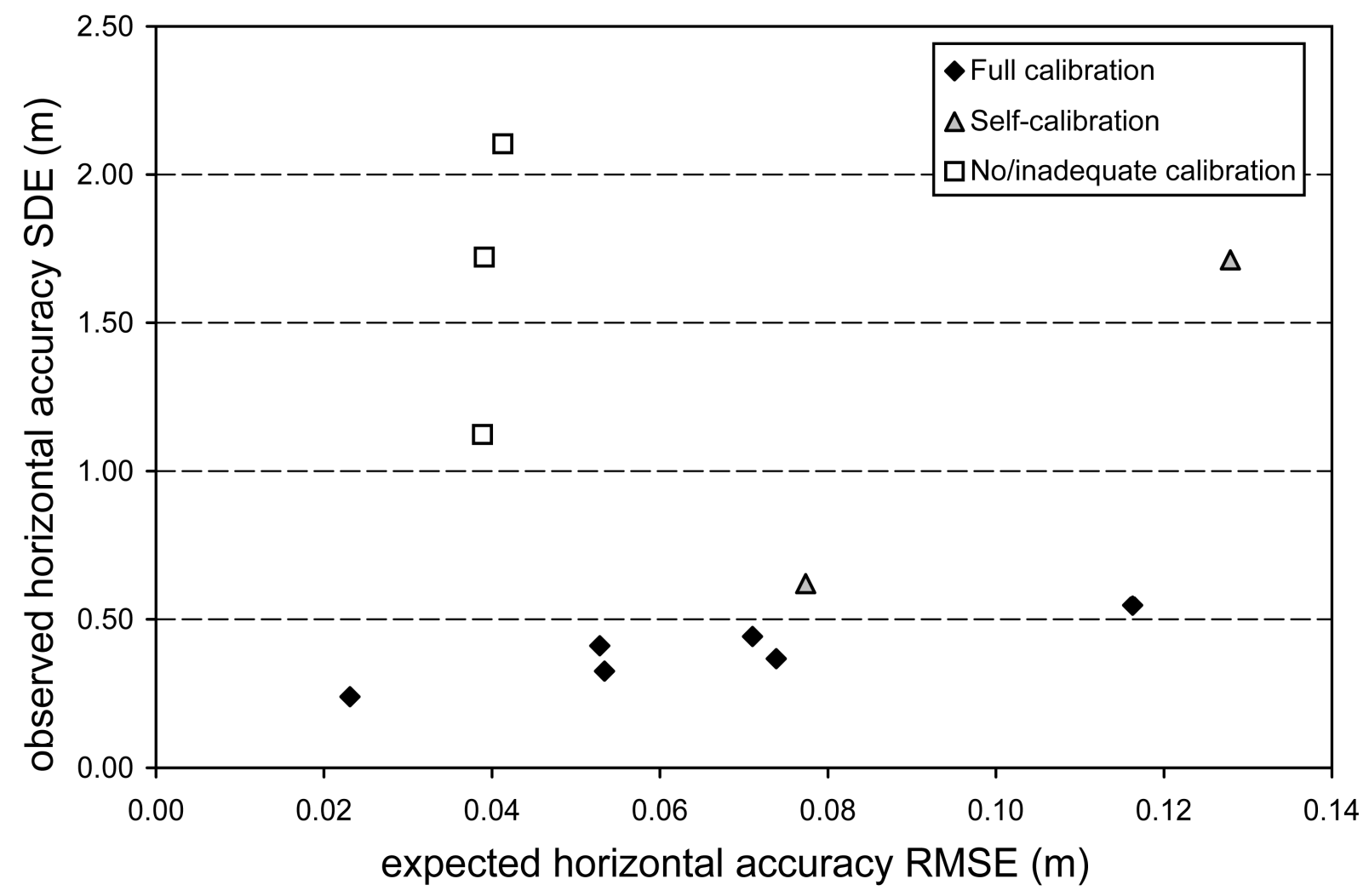

Figure 3. Comparison between expected horizontal accuracy (RMSE) and observed horizontal accuracy (SDE); the epochs are grouped according to their calibration status. 


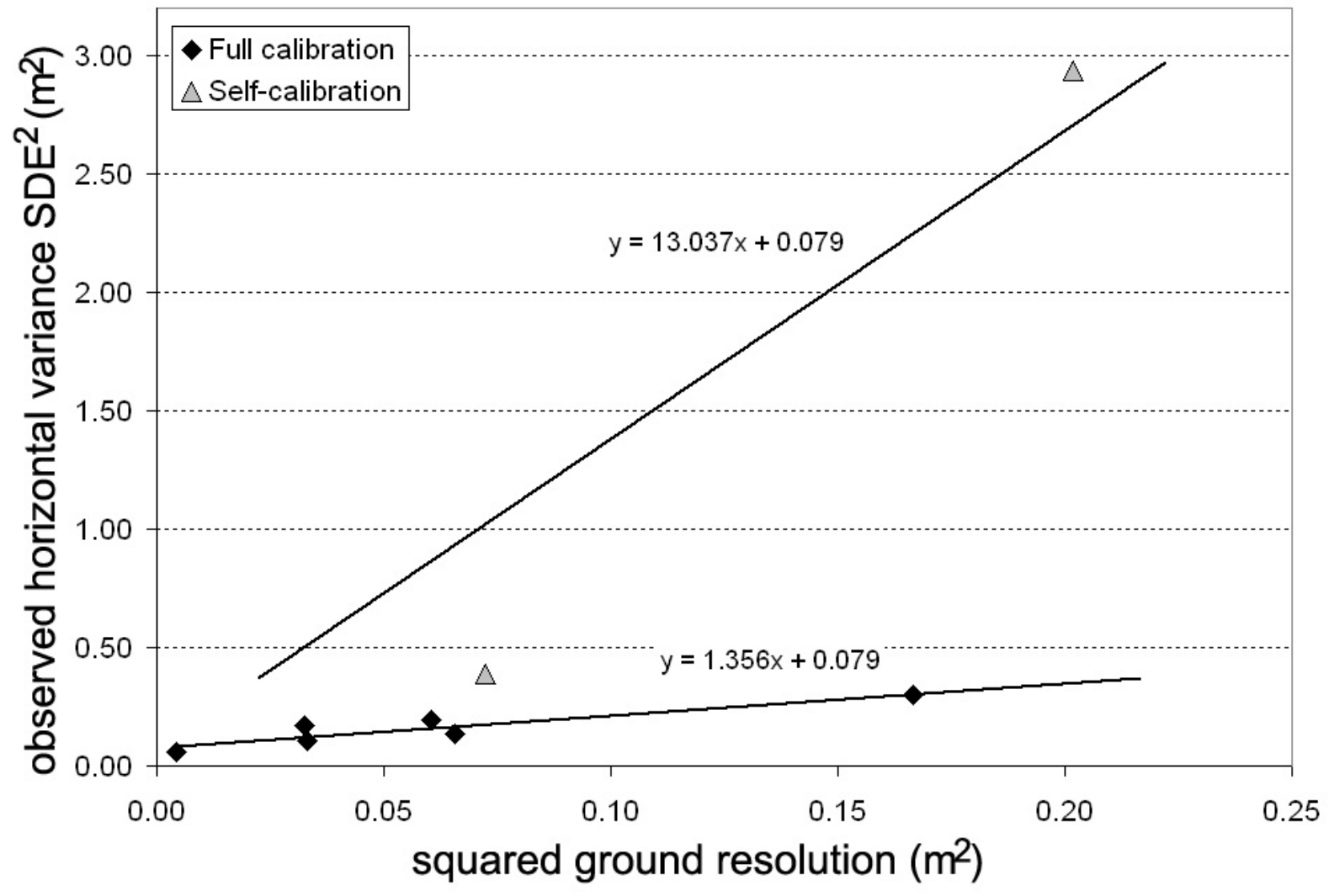

Figure 4. Relation between ground resolution and observed horizontal accuracy (SDE). 

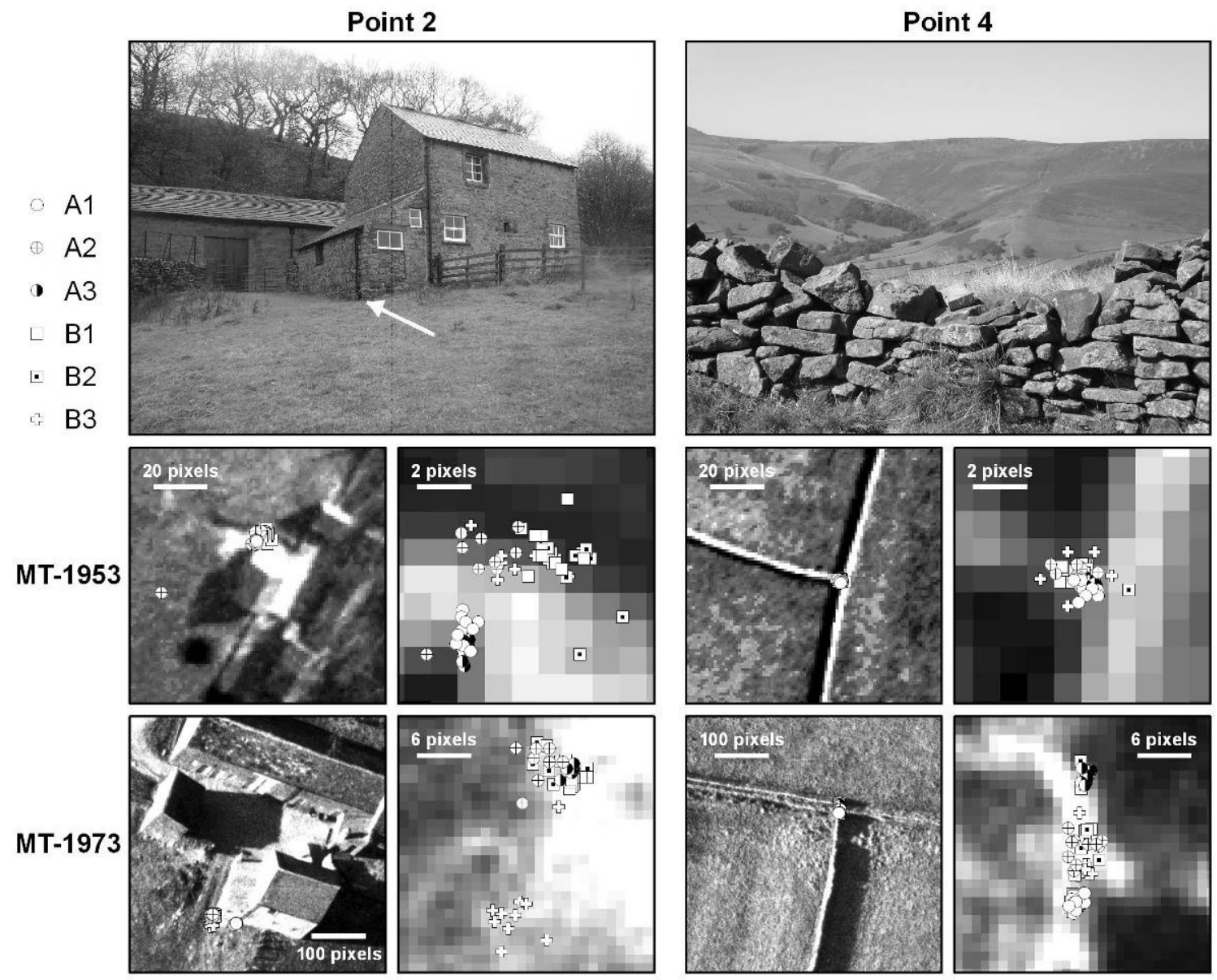

Figure 5. Two of the test points, typically used for ground control in the case-studies. Upper pictures show the objects in the field: the corner of a farm house (indicated by arrow) and a dry stonewall used as field boundary. Lower images show the test points on excerpts from the aerial photographs. The point clouds represent all individual measurements by the six operators. The variance of the measurements 'within' and 'between' operators is clearly demonstrated by the clustering of point clouds. 


\section{Quality of source data Quality of calibration data Quality of control}

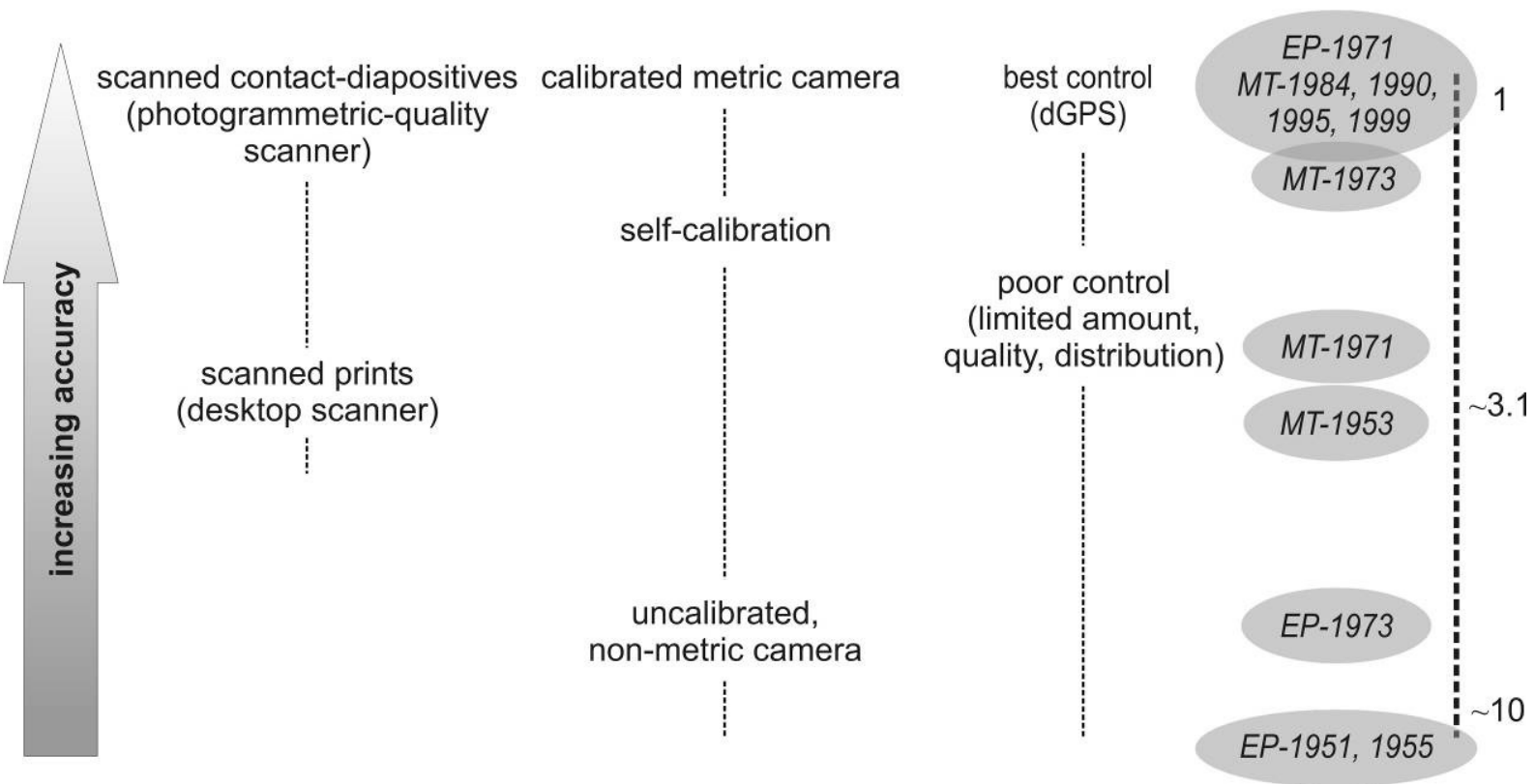

Figure 6. The effects of various factors on data accuracy; the categories on top provide the highest achievable accuracy, decreasing downwards. The scale bar on the right and position of the epochs from this study are an approximation. 